EESTI NSV TEADUSTE AKADEEMIA TOIMETISED 1954. III kd., nr. 4

ИЗВЕСТИЯ АКАДЕМИИ НАУК ЭСТОНСКОЙ ССР 1954. Том III. № 4

\title{
BIOLOOGILISI NÄHTUSI LIIVAKIRSI (CERASUS BESSEYI BAIL.) KASUTAMISEL PLOOMIPUUDE POOKEALUSENA
}

\section{J. PALK}

Eesti NSV Teaduste Akadeemia Taimekasvatuse Instituudi puuviljanduse sektor on alates 1945. aastast tegelnud liivakirsi seemikute kui ploomipuu nõrgakasvuliste pookealuste küsimusega.

Küsimus on esile kerkinud selle tõttu, et tugevakasvulistel alustel hakkavad mitmed ploomipuusordid vilja kandma hiljem kui nõrgakasvulistel alustel. Samuti tuleb arvestada kohalikke klimaatilisi tingimusi, sest Eesti NSV siserajoonides langeb temperatuur talvel tunduvalt madalamale kui saartel ja rannikualal, mistõttu seal külmad tugevakasvulistel alustel kasvavaid ploomipuid sageli enne nende täielikku viljakandmisikka jõudmist tõsiselt kahjustavad. Nõrga kasvuga alustele poogitud ploomipuud põõsakujulistena on aga külma vastu kergemini kaitstavad ja annavad viljakandmise varajase alguse juures ka head saaki. Senini aga puudub meil Eesti NSV oludes ploomipuule sobiv nõrga kasvuga alus.

Kitsapiirilise katse teostamise käigus selgus, et selekteerimata liivakirsi seemikud suuremalt osalt ei ole Eesti NSV-s levinud ploomisortidele sobivateks pookealusteks. Uhtlasi on liivakirsi seemik-alustel kasvavate ploomipuude juures ilmnenud bioloogilisi nähtusi, mis lisaks teoreetilistele tulemustele võivad olla praktiliseks teenäitajaks ploomipuude kultuursortidele alusteks sobivate liivakirsi üksikute (vegetatiivselt paljunevate) tüüpide selekteerimisel.

Katses kasutatud liivakirsi seeme saadi 1945. aastal Altai PuuviljaMarjakasvatuse Katsejaamast. Sellest seemnest kasvatatud 1-aastased seemikud istutati 1946. a. kevadel puukooli ja poogiti suvel silmistamise teel - 1200 seemikut mitmesuguste hapu- ja maguskirsi sortidega ja 1200 seemikut kahekümne ploomipuu kultuursordi, nelja ploomipuu metsiku vormi (Prunus spinosa L., Prunus cerasifera Ehrh., Prunus nigra Ait, Prunus ussuriensis K. et K.) ning kolme ploomipuu vegetatiivse alusetüübi (mürobolaan tp. B, Black Damas C, Akermanni ploom (Marunke)) pookepungadega.

1947. a. kevadel kasvas pookepungi välja ploomipuudel $96 \%$ ja kirsipuudel $2 \%$. Enamik kirsipuu-okulaatidest murdus juba suvel pookimiskohalt lahti. Sügiseks jäi järele ainult viis okulaati. Neist neli kuivasid järgmisel talvel. Seega säilis kirsipuudest ainult üks viie tugeva ennakvõrsega $68 \mathrm{~cm}$ pikkune „Diemetzi amarelli” okulaat.

Ploomipuude okulaadid liivakirsi-alusel kasvasid ja ennakvõrsusid hästi ning saavutasid sügiseks vastavalt sortidele pikkuse keskmiselt $1,17-1,78 \mathrm{~m}$. Sügissuvel korraldatud vaatlustel selgus, et rida ploomipuusorte ei kasva liivakirsi-alusega hästi kokku. Tugevate tuulte tõttu osa „Wilhelmine 
Späthi”, „Varajase sinise”, „Wangenheimi säilisploomi”, „Hariliku säilisploomi” ja „Rohelise renkloodi” okulaatidest murdus pookimise kohalt lahti ning enamik samade sortide säilinud okulaatidest vajus viltu. Seda nähtust esines ka teiste sortide juures, kuid mainitutega võrreldes palju vähem.

Vaatamata tugevale kasvule lõpetasid liivakirsi-alusel olevad ploomipuuokulaadid kasvu sügisel varakult ja nende lehed varisesid lühikese ajaga.

1947. a. detsembris, mil lumekate puudus, ei kahjustanud külm mullapinna läheduses levivat liivakirsi juurekava, kuigi kolmel ööl oli temperatuur $-20^{\circ} \mathrm{C}$.

1948. ja 1949. aasta kevadel istutati 1946. aastal liivakirsi seemikutele poogitud ploomipuudest katseaeda 147 istikut ja liivakirsi-alusel ainukesena säilinud kirsipuu „Diemetzi amarelli” istik. Ploomipuu istikud läksid hästi kasvama ja moodustasid sügiseks enamikus ilusad $40-60 \mathrm{~cm}$ pikkuste aastakasvudega madalatüvelised põõsaspuud.

Katseaeda istutatud 147-st liivakirsi-alusele poogitud ploomipuust on kuue aasta jooksul hävinud 49 puud hõbelehisusse (Stereum purpureum
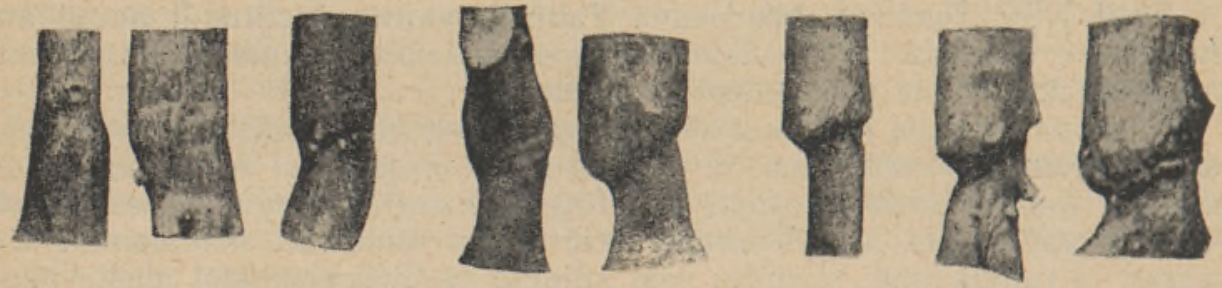

$a$

$b$

c

Joon. 1. Näiteid ploomipuusortide ja selekteerimata liivakirsi seemikute heast (a), enamvähem rahuldavast (b) ja halvast (c) kokkukasvamisest.

Pers.) haigestumise, juurekaela kõdunemise ning aluse ja pookesordi halvasti kokkukasvamise tagajärjel, mõne sordi all väga peenikeseks jäänud aluse katkimurdumise tõttu tugeva tormi ajal ning liivakirsi kääbusvormidel kasvavate puude väga lühikese eluea tõttu.

Et katses on suur arv mitmesuguse põlvnemisega ploomipuu kultuursorte ja metsikuid tüüpe, mis on poogitud morfoloogiliselt tugevasti erinevatele liivakirsi seemikutele, siis nende puude kasvamisel katseaias selgus, et mitte ainult pookesortidel, vaid ka ühe pookesordi piires üksikutel puudel esines kasvus ja eriti alusega kokkukasvamises suuri erinevusi.

Sellest võib järeldada, et liivakirsi seemikute hulgas esineb ka sisemiste omaduste poolest tunduvalt erinevaid isendeid. Seda kinnitavad vaatlused puukoolis ja seemnekandjate istanduses, kus selgus, et mitmed liivakirsi seemikud kasvu alguse ja lõpu, lehtede varisemise aja, puuosa tiheduse ja muude tunnuste poolest kalduvad seemikute enamiku vastavatest keskmistest näitajatest tunduvalt kõrvale.

Peale muude põhjuste (juurekaela kõdunemine jne.) peetakse liivakirssi halvaks pookealuseks veel sellepärast, et nõrga juurekava tõttu vajuvad liivakirsi-alusel kasvavad puud sageli viltu. See on osalt tingitud sellest, et alustena kasutatavate liivakirsi seemikute hulgas esineb väga nõrga kasvu ja nõrga juurekavaga või väga pehme puuosaga isendeid.

Puukoolis ja katseaias läbiviidud vaatlused tõestasid, et suures enamuses oleneb puude viltuvajumine sellest, kas pookeosa, olenevalt alusega kokkukasvamisest, toidab alust selle juurekava tugevaks arendamiseks küllalt hästi või mitte. Toodud seisukoha tõepärasust kinnitab see, et hulgaliselt vajuvad viltu puud just nendest sortidest (,Wilhelmine Späth", „Wangenheimi säilisploom”, „Harilik säilisploom” jt.), mis liivakirsi-alu- 
sega halvasti kokku kasvavad. Vaatlused ja mõõtmised näitasid, et liivakirsi tugevama kasvuga pookimata isendid kujundavad ka kultuuris kasvades kỗige enam kuni 1,5 m körguse, mullapinna läheduses levivate juurtega põõsa, mille tüve läbimõõt seitsmendal kasvuaastal on $4-5 \mathrm{~cm}$.

Kuidas aga liivakirsi seemikutega üldiselt hästi kokkukasvavad pookesordid „Varajane punane”, „Liivi kollane munaploom” ja „Emma Leppermann" liivakirsi kui aluse jämeduse kasvu ja juurekava leviku sügavust mõjutavad, näitab see, et loetletud pookesortide all on aluse jämedus seitsmendal kasvuaastal $8-10 \mathrm{~cm}$ ning nende puude aluste jämedamad juured ulatuvad kuni $1,5 \mathrm{~m}$ sügavuseni.

Liivakirsi seemikute ja neile poogitud ploomipuusortide ning metsikute tüüpide kokkukasvamine on väliselt väga lahkuminev (joon. 1). Kokkukasvamise välist kuju aluseks võttes võib katses olevaid ploomipuusorte ja metsikuid tüüpe liivakirsi seemikutega kokkukasvamise suhtes rühmitada nii, nagu näitab tabel 1 .

Tabel 1

Vaatlusandmed liivakirsi aluse kokkukasvamisest üksikute ploomisortidega ja ploomi metsikute tüüpidega.

\begin{tabular}{c|c|c}
\hline $\begin{array}{c}\text { Aluse ja pookosa } \\
\text { kokkukasvamise aste }\end{array}$ & $\begin{array}{c}\text { Kokkukasvamise väline } \\
\text { kuju }\end{array}$ & Pookesordid \\
\hline
\end{tabular}

Hea kokkukasvamine

Enam-vähem rahuldav kokkukasvamine

Täiesti halb kokkukasvamine
Osal puudest on alus pookosast jämedam

Alus ja pookosa on peaaegu vōrdse jämedusega vōi alus on pookosast veidi peenem

Alus on pookosast märgatavalt peenem

Alus on pookosast tunduvalt peenem, kuid nende üleminek on sujuv

Alus on pookosast palju peenem vōi suurel enamikul puudest esineb aluse ning pookosa kokkukasvamise kohal tugevaid koorelōhesid
Liivi kollane munaploom Varajane punane

Opata

Ida kaunitar

Prunus nigra

Prunus ussuriensis

Suur punane munaploom

Suur kollane munaploom

Emma Leppermann

Ruth Gerstetter

Edinburgi ploom

Renklood ternovõi

Prunus cerasifera

Mürobolaan tp. B

Black Damas C

Akermanni ploom (Marunke)

Prunus spinosa

Tragöödia

Jefferson

Lüzelsachsi varajane

Ontario

Varajane sinine

Viktooria *

Wilhelmine Späth

Harilik säilisploom

Wangenheimi säilisploom

Suur roheline renklood

* Osal kolme viimase sordi puudel esineb aluse ja pookosa kokkukasvamise kohal tugevaid koorelōhesid.

Ploomipuusortide ja metsikute tüüpide niisugune rühmitamine selekteerimata liivakirsi seemikutega kokkukasvamise järgi on ainult üldjooneline, sest rühmade vahele ei saa tömmata kindlaid piire, kuna pookealustega 
rahuldavalt kokkukasvavate sortide rühmas esineb niisuguseid ploomipuusorte, mis alustega kokkukasvamise keskmise tulemuse poolest on suhteliselt lähedased ka halvasti kokkukasvavate sortide rühmale („Ontario", „Varajane sinine”, „Viktooria”).

Täpsemad vaatlused näitasid, et kokkukasvamisel liivakirsi seemikute kui pookealustega esineb pookesortide piirides tüüpilise keskmise või sellele lähedaste tulemuste kõrval ka üksikuid suuremaid kõrvalekaldumisi, mille kohta on toodud järgnevad näited.

Uheksast liivakirsi-alusele poogitud „Wilhelmine Späthi” sorti ploomipuust (nimetatud sort kasvab liivakirsiga halvasti kokku) hävis neli puud juba katseaias kasvamise teisel aastal, pookimise kohalt lahtimurdumise tagajärjel. Viiest senini säilinud puust on kolmel aluse ja pookosa kokkukasvamine väliste tunnuste järgi halb. Puud ei anna katseaias kasvamise kolmandast aastast alates nimetamisväärset juurdekasvu, võrade kõrgus on keskmiselt $1,5 \mathrm{~m}$, viljakandmine üle aasta, $5-10 \mathrm{~kg}$ puu kohta, mis sordile omast saagikust ja puude vanust arvestades on rahuldav kuni hea. Kõik kolm puud näitavad ilmselt raugastumise tunnuseid.

Seevastu on aga üks "Wilhelmine Späthi” sorti ploomipuu kasvanud istutamisest alates igal aastal hästi, omab püstjat, tugevate okstega 3 meetri kõrgust võra ning on täiesti elujõuline. Sellel puul on alus pookosast umbes $1 \mathrm{~cm}$ võrra peenem ja nende kokkukasvamise kohal esineb võrdlemisi nõrk koorelõhe (teistel samasordilistel puudel on alus pookosast umbes 3-4 cm peenem). Peale nimetatud „Wilhelmine Späthi” sorti puu on katseaias veel kaks hästi kasvavat puud liivakirsiga üldiselt halvasti kokkukasvava kuue „Varajase sinise” sorti ploomipuu hulgas. Aluse ja pookosa peaaegu võrdse jämeduse, nende hea kokkukasvamise, pookosa hea kasvu ja puude elujōulisuse tōttu võib need kolm puud lugeda liivakirsiga rahuldavalt kuni hästi kokkukasvavateks.

Liivakirsiga halvasti kokkukasvavate sortide rühmas esineb ka niisuguseid üksikuid puid (üks „Varajane sinine”, üks „Wilhelmine Späth” ja üks „Harilik säilisploom” - viimane hävis 1953. aastal hõbelehisuse tagajärjel - ning kirsipuudest ainukesena säilinud „Diemetzi amarell”), mis puukoolis ja esimestel aastatel katseaias kasvasid enam-vähem rahuldavalt. Alates aga õitsemisest ja viljakandmisest, s. o. pookosa kolmandast-neljandast eluaastast, muutus nende puude aastane juurdekasv minimaalseks või lakkas peaaegu täielikult. Osal puudest esines aga neljandal kuni kuuendal pookosa kasvamise aastal pärast mõõdukat okste kärpimist (kusjuures väetamise ja mullaharimise tingimused jäid endiseks ning hea viljakandmine jätkus) intensiivne vegetatiivne kasv, mis ühel nendest kestab juba kolm aastat. Vaatlused näitasid, et nimetatud puud ei ole muutunud omajuurseteks.

Eespoolkirjeldatud nähtustega võrreldes negatiivses suunas järsult kõrvalekalduvaid üksikuid puid esineb ka liivakirsi seemikutega üldiselt hästì kokkukasvavate sortide rühmas. See näitab, et selekteerimata liivakirsi seemikud on pookealusteks sobimatud ka nendega üldiselt hästi kokkukasvavatele ploomipuusortidele.

Kui arvestada, et ühe ja sama sordi kõik pookosad on praktiliselt konstantsed, siis tõestavad kirjeldatud nähtused, et alustena kasutatud noorte liivakirsi seemikute hulgas tüüpilisest keskmisest ja sellele lähedastest isenditest koosneva suure enamiku kõrval esinevad üksikud väga tugevasti kõrvalekalduvate ja väga paindlike sisemiste omadustega isendid.

Neli aastat kestnud katsed kinnitavad, et suur osa liivakirsi seemikutest on pistokste ja kuhjevõrsikute meetodil vegetatiivselt paljundatavad (joon. 2). Seepärast võib loota, et igas, eriti aga liivakirsiga halvasti 
kokkukasvavate sortide rühmas ette tulnud üksikud nende sortidega hästi kokkukasvavad tugevama kasvuga isendid võimaldavad selektsiooni teel saada vegetatiivselt paljunevaid liivakirsi tüüpe, mis sobivad alusteks senisest laialdasemale sortimendile. Selle kõrval tuleb uurida ka vastavate liivakirsi tüüpide generatiivsete järglaste omadusi nende kui pookealuste seisukohalt.

Ploomipuudele alusteks sobivate liivakirsi tüüpide selekteerimisel ei tule lähtuda ainult aluse tüübi ja pookesordi heast kokkukasvamisest, vaid ka puude kasvutugevusest, viljakusest, ilmastikule, haigustele ja juurekaela kõdunemisele vastupidavusest ning eluea pikkusest antud alusetüübil.

Eesti NSV Teaduste Akadeemia Taimekasvatuse Instituudi puuviljanduse sektori katsepuukoolis ja katseaias teostatud katsete tulemusena on selgunud andmed külmakindluse, viljakuse ja kasvutugevuse suhtes, kuid andmed haigustele ning juurekaela kõdunemisele vastupidavuse ja eluea pikkuse suhtes pole veel küllaldased.

1. Külmakindluse suhtes tuleb mainida, et liivakirsi-alusel kasvavad, suhteliselt külmaõrnad ploomipuusordi "Ontario" okulaadid kannatasid külma tõttu 1948. a. jaanuaris, mil temperatuur kaks korda järsult langes pakaseni $-30^{\circ} \mathrm{C}$, märgatavalt vähem kui sama sordi okulaadid mürobolaani ja juuliploomi seemikalustel. Seejuures oli aga sortide „Edinburgi ploom" ja „Varajane sinine” okulaatide külmakahjustus kõikidel loetletud alusetüüpidel võrdne.

2. Liivakirsi-alusel kasvavate ploomipuude saagi registreerimise andmed näitasid sordi piires suuri erinevusi. Nii oli ühevanustelt puudelt neljal esimesel saagiaastal saadud viljade kogukaal puu kohta „Emma Leppermannil” 11,5-20,7 kg, „Edinburgi ploomil” 33,3-69,3 $\mathrm{kg}$ ja „Liivi kollasel munaploomil" $9,8-30,8 \mathrm{~kg}$.

3. Katsepuude võrade mõõtmise andmed näitasid, et „Liivi kollasel munaploomil” kui liivakirsiga üldiselt hästi kokkukasvaval sordil erinevad 7-aastased puud võrade kõrguselt kuni $1,2 \mathrm{~m}$ ja laiuselt kuni $0,8 \mathrm{~m}$ võrra.

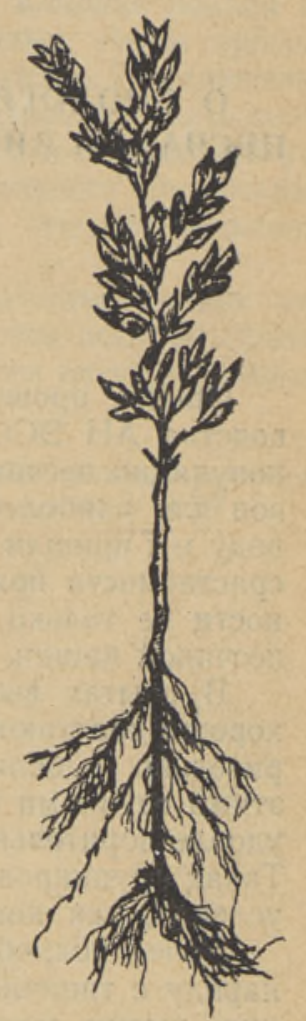

Joon. 2. Uhe vegetatiivselt hästipaljuneva liivakirsi tüübi pistoks teise kasvuaasta kevadsuvel.

4. Luuviljaliste mädaniku (Sclerotinia cinerea Schroet.) vastu osutus kindlamaks liivakirsi-alusel kasvav „Edinburgi ploom” ja vastuvõtlikumaks "Liivi kollane munaploom", võrreldes samade sortidega mürobolaani seemikaluseil.

Kokku võttes võib öelda, et selekteerimata liivakirsi seemikutele poogitud ploomipuude vastupidavus ilmastikule ja haigustele ei ole kõigil sortidel ühesugune. See ei olene alati ainult alusest, vaid vähemalt mõnel juhul aluse ja pookesordi omaduste kombinatsioonist. Lisaks erinevustele pookosade alustega kokkukasvamisel erinevad puud sordi piires tunduvalt ka kasvutugevuse ja viljakuse poolest.

Kui üksikute ploomisortide alustega kokkukasvamise, viljakandmise ning ilmastikule vastupidavuse osas on liivakirsi tüüpide kui pookealuste selektsiooni läbiviimiseks andmed juba küllaidased, siis on need puude 
eluea pikkuse, juurekaela kõdunemisele ning haigustele vastupidavuse suhtes veel puudulikud.

Lõpuks tuleb märkida, et meie ploomipuusortidele alusteks sobivate liivakirsi tüüpide selektsioon nõuab pikka aega ja on suhteliselt raske seepärast, et lahendamist vajab rida väga erinevaid küsimusi.

Eesti NSV Teaduste Akadeemia

Taimekasvatuse Instituut

Saabus toimetusse 11. V 1954

\title{
О БИОЛОГИЧЕСКИХ ЯВЛЕНИЯХ ПРИ ИСПОЛЬЗОВАНИИ ПЕСЧАНОЙ ВИШНИ (Cerasus Besseyi Bail.) В КАЧЕСТВЕ ПОДВОЯ для сливы
}

\author{
Я. Ю. ПАЛЬК
}

Резюме

Опыты, проведенные в секторе плодоводства Института растениеводства АН ЭССР, показали, что не подвергавшиеся селекции сеянцы популяции песчаной вишни (Cerasus Besseyi Bail.) непригодны как подвои для наиболее распространенных у нас сортов сливы. К такому выводу мы пришли на основании полученных в опытах данных о различной срастаемости привоя с подвоем, силе роста, урожайности и долговечности не только у деревьев разных сортов сливы, привитых на сеянцы песчаной вишни, но также и у деревьев одного сорта.

В опытах выяснилось также, что с большей частью таких сеянцев хорошо срастаются сорта из группы яичных слив и совсем неудовлетворительно - большинство сортов из групп венгерок и ренклодов. Между этими группами имеется переходная группа сортов сливы, срастающихся удовлетворительно с большей частью не подвергнутых селекции сеянцев. Такая группировка сортов сливы по срастаемости с песчаной вишней условна, так как между группами нельзя установить твердых границ.

Более подробное изучение показало, что в пределах одного сорта, наряду с типичными, средними, и близкими к ним результатами срастания, имеют место отдельные значительные отклонения, характеризующиеся следующими особенностями: 1) в группе плохо срастающихся с сеянцами песчаной вишни сортов слив, где большинство деревьев погибает от перелома в месте срастания или же быстро стареет, встречаются отдельные деревья, отличающиеся жизнеспособностью и сильным ростом уже в год прививки; 2) в той же группе встречаются отдельные деревья, развивавшиеся в первые годы более или менее удовлетворительно, но рост которых, начиная с первого плодоношения, прекращается совсем или же происходит очень медленно; после $1-3$ лет такого «прозябания» внезапно возобновляется мощный рост; 3) отклонения в сторону плохого срастания привоя с подвоем встречаются также в группе хорошо срастающихся сортов.

В опытах выяснилось также, что: 1) некоторые привитые на песча ную вишню сливовые деревья легко валятся от ветра, что зависит в первую очередь от того, снабжается ли подвой в достаточной мере пластическими веществами для образования сильной корневой системы; 2) влияние сеянцев песчаной вишни как подвоя на устойчивость дерева в отношении климатических условий не проявляется в одинаковой степени у всех сортов-привоев; 3) кроме различий в срастаемости с подвоем песчаной вншни, деревья в пределах сорта различаются значительно 
также по силе роста, урожайности и долговечности. Отсюда следует, что не подвергавшиеся селекции сеянцы песчаной вишни непригодны как подвой даже для хорошо срастающихся с ними сортов сливы.

Те сеянцы песчаной вишни, которые в качестве подвоя наряду с хорошим срастанием с привоем обеспечили деревьям (в пределах хорошо, удовлетворительно и плохо срастающихся сортов) также сильный рост, неполегаемость, жизнеспособность и невыпреваемость корневой шейки, указывают направление селекции существующих форм песчаной вишни как подвоя для сливы. Для обеспечения одинакового влияния подвоя на рост, урожайность и долговечность деревьев необходимо, чтобы пригодные для прививки формы подвоя размножались вегетативно. Предпосылки для этого имеются, так как, по данным опытов, значительная часть сеянцев песчаной вишни размножается вегетативно хорошо или удовлетворительно. Наряду со способами вегетативного размножения необходимо изучить также особенности генеративного потомства этих форм вишни как подвоя.

Селекция форм песчаной вишни, пригодных в качестве подвоя для сливы, требует длительной работы и затруднена тем, что попутно приходится решать ряд вопросов о причинах несовместимости песчаной вишни как подвоя с сортами сливы.

Институт растениеводства Академии наук Эстонской ССР
Поступила в редакцию 11 V 1954 